\title{
Síndrome de DRESS secundario a suplemento yodado
}

\author{
Blanca Alonso-Martínez, Juan Cantón-de-Seoane, Nagore Lois-Martínez, Pablo del-Valle-Loarte \\ Servicio de Medicina Interna, Hospital Universitario Severo Ochoa, Leganés, Madrid, España
}

Recibido: 06/09/2021

Aceptado: 11/11/2021

En línea: 31/12/2021

Citar como: Alonso-Martínez B, Cantón-de-Seoane J, Lois-Martínez N, del-Valle-Loarte P. Síndrome de DRESS secundario a suplemento yodado. Rev Esp Casos Clin Med Intern (RECCMI). 2021 (dic); 6(3): 18-21. doi: 10.32818/reccmi.a6n3a7.

Cite this as: Alonso-Martínez B, Cantón-de-Seoane J, Lois-Martínez N, del-Valle-Loarte P. DRESS syndrome secondary to iodinated supplement. Rev Esp Casos Clin Med Intern (RECCMI). 2021 (Dec); 6(3): 18-21. doi: 10.32818/reccmi.a6n3a7.

Autor para correspondencia: Blanca Alonso-Martínez. blancaalonsomartinez@hotmail.com

\section{Palabras clave}

$\checkmark$ Yodo

- Síndrome de DRESS

$\triangleright$ Eosinofilia

\begin{abstract}
Resumen
El síndrome de DRESS (Drug Reaction with Eosinophilia and Systemic Symptoms) es una reacción adversa grave medicamentosa que incluye una erupción cutánea extensa, anomalías hematológicas (eosinofilia), linfadenopatías y afectación de órganos vitales como el hígado, el riñón y los pulmones. Presentamos el caso de una mujer lactante de 37 años con diagnóstico de síndrome de DRESS secundario a la ingesta de suplementos de yodo con afectación pulmonar grave. Dada la potencial gravedad de este síndrome, y que los suplementos nutricionales pueden conseguirse sin receta médica, creemos interesante compartir este caso, para ayudar al médico a sospechar esta posibilidad, y guiar en el diagnóstico y en el manejo.
\end{abstract}

\begin{tabular}{l} 
Keywords \\
\hline lodine \\
$\triangleright$ DRESS Syndrome \\
$\triangleright$ EOsinophilia \\
\end{tabular}

\section{Puntos destacados}

- EI DRESS es un síndrome de hipersensibilidad a fármacos. En su patogenia influyen factores genéticos, inmunológicos y virales.

- No hay ninguna prueba definitiva, siendo útiles los criterios diagnósticos.

- Se debe evaluar la afectación de órganos vitales, como la afectación pulmonar o la cardíaca.

\section{Introducción}

El síndrome de DRESS fue descrito por primera vez en 1996 por Bocquet et al. y se define como una reacción a fármacos con eosinofilia y síntomas sistémicos (Drug Reaction with Eosinophilia and Systemic Symptoms)' Se caracteriza por una latencia de entre dos y hasta ocho semanas después de la administración del fármaco y por un curso prolongado, con frecuentes recaídas a pesar de su suspensión².
Dada la gran diversidad de las manifestaciones clínicas de este cuadro, así como la inexistencia de una prueba clínica concluyente, se han formulado diferentes criterios diagnósticos, como los del Japanese group's criteria y los criterios del Registro Europeo de las Reacciones Adversas Cutáneas Severas (RegiSCAR, por sus siglas en inglés). Estos últimos, más comúnmente utilizados, desarrollan un sistema de puntuación para evaluar los casos de síndrome de DRESS, como «no», «posible», «probable», «definitivo»3.

Los fármacos más frecuentemente implicados con el síndrome de DRESS son el alopurinol, la carbamazepina y la dapsona. Por otro lado, en la patogenia de este síndrome se ha relacionado una posible susceptibilidad genética a algunos fármacos según la presencia de determinados haplotipos (HLA-B*58:01 y susceptibilidad al alopurinol, HLA-A * 31: 01 y la carbamazepina, y HLA-B*13:01 y la dapsona) ${ }^{4}$.

También se ha relacionado el estado inmunológico del paciente en su patogenia, así como la participación viral en forma de reactivación de VHS-6, VHS-7 y CMV; siendo especialmente frecuente la reactivación del VHS-6 (hasta del 60\% en algunas series), por lo que se incluye en los criterios diagnósticos 5 . 


\section{Caso clínico}

\section{Antecedentes y enfermedad actual}

Mujer de 37 años, lactante, sin antecedentes patológicos de interés. Sin hábitos tóxicos. Sin medicación habitual salvo suplementos nutricionales (ácido fólico y yodo). Dos semanas previas a la consulta en Urgencias, cambió la formulación del suplemento yodado que tomaba de forma habitual por otro similar.

Acudió a Urgencias, por fiebre de $38,5^{\circ} \mathrm{C}$, disnea, tos y lesiones vesiculosas cutáneas muy pruriginosas de más de 10 días de evolución. Además, presentaba diarrea y vómitos. No había otras personas en su entorno que tuvieran síntomas similares, así como tampoco contacto con animales o viajes de riesgo.

\section{Exploración física}

La paciente presentaba afectación del estado general, temperatura $37,5^{\circ} \mathrm{C}$, tensión arterial 107/64 mmHg, taquipnea con saturación 90\% basal y frecuencia cardíaca 105 latidos por minuto. También presentaba lesiones cutáneas en diferentes estados evolutivos: pápulas, vesículas y costras en cuello, brazos, tronco y piernas y edema de vulva (Figura 1).

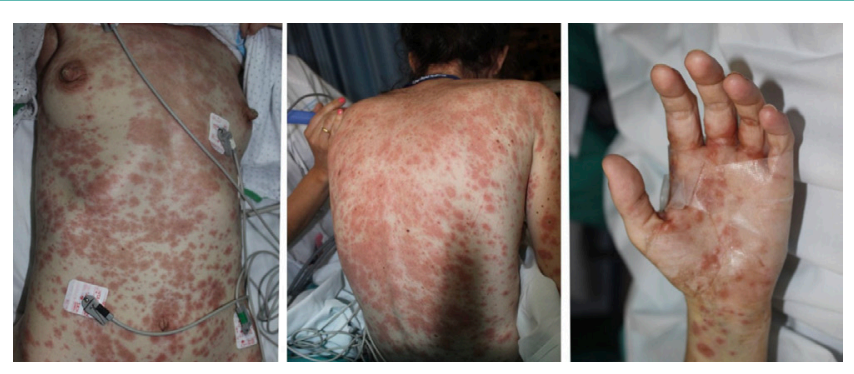

Figura 1. Exantema generalizado
La auscultación cardiopulmonar no mostró sonidos patológicos, y el abdomen era doloroso a la palpación difusa sin signos de irritación peritoneal.

\section{Pruebas complementarias}

Los resultados del análisis de laboratorio se presentan en la tabla 1.

El ecocardiograma transtorácico no tuvo hallazgos patológicos. La tomografía computarizada (TC) torácica presentaba: adenopatías mediastínicas paratraqueales superiores bilaterales, paratraqueales inferiores bilaterales, subcarinales, las de mayor tamaño de $2 \mathrm{~cm}$ de diámetro trasverso corto e hiliares bilaterales. Mínimo derrame pleural bilateral y un patrón difuso pulmonar caracterizado por engrosamiento fino de los septos interlobulillares de forma bilateral y simétrica (Figura 2).

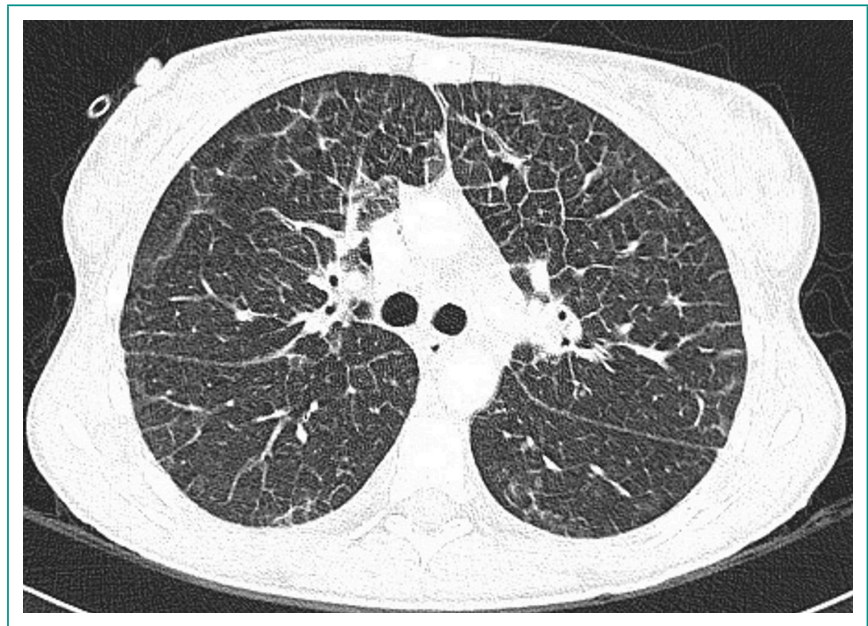

Figura 2. Patrón difuso pulmonar caracterizado por engrosamiento fino de los septos interlobulillares de forma bilateral y simétrica.

\section{Analítica básica}

- Bioquímica: Glucoas 83 mg/dL (76-110); Creatinina 0,77 mg/dL (0.5-1.10); Sodio 140 meq/L (135-145); Potasio 4,4 meq/L (3,5-4,5); Proteínas totales 7,6 g/dL (6,6-8,7); ALT 765 U/L (0-33); GGT 75 U/L (7-32); PCR 229 mg/dL (0-5); LDH 253 U/L (100-250).

- Hemograma: Hb 14,40 g/dL (12-16);VCM 86,90 fl (80-94); Pqts 298.000 miL/micL (130-400); Leucocitos 14.280 mil/mcL (4,80-10,80); Eosinófilos 3.760 mm³ (0-0,8).

- Coagulación:TP 17,30 seg (9,13); I. de Quick 54\% (10-100);TTPa 33 seg (<34).

\section{Estudios microbiológicos}

- Serologías Parainfluenza, Adenovirus, VRS, CMV, CHD, VEB: negativas.

- Serologías VIH, HTL1-2: negativas; Serologías virus hepatotropos: negativas.

- Serología Treponema pallidum; negativa.

- Serologías Strongyloides, Anisakis, Filarias, Schistosoma, Toxocara, Fasciola, Trichinella, Hidatidosis, Leishmania: negativas.

- PCR VHS-6, VHS-7 y VHS-8: negativas.

- PCR Sarampión, Parvovirus, Rubeola: negativas.

\section{Marcadores autoinmunitarios}

- Ac. Antinucleares 0,44 U/mL (0-0.85), ENA 0,2 U/mL (0-1,0), Ac antimembrana basal glomerular; negativo; c-ANCA, p-ANCA negativos.

- C3 $103 \mathrm{mg} / \mathrm{dL}(84-175) ; C 417 \mathrm{mg} / \mathrm{dL}(10-40)$

\section{Inmunología}

- Triptasa 4,45 ng/mL (0,00-11,50); Enzima Convertidora de Angiotensina: negativa.

- Espectro electroforético: descenso de la fracción de albúmina, aumento de reactantes de fase aguda.

- $\operatorname{lgA} 131$ mg/dL (70-400); IgM 91 mg/dL (39-258); IgG 843 mg/dL (700-1.600); IgE 476 MG/DL (0-100).

\section{Citometría de flujo y biología molecular en sangre periférica}

- El fenotipo de la población linfoide en SP indica un número de células B bajo (5\%) y policlonal.

- Cociente CD4/CD8 normal.

- Estudio de clonalidad B y T negativo.

- Estudio de translocación negativo.

CHD: enfermedad de Chagas. CMV: citomegalovirus. PCR: proteína C reactiva. VHS: virus herpes simple. VEB: virus Epstein Barr. VRS: virus respiratorio sincitial.

Tabla 1. Resultados de hemograma, bioquímica, estudios microbiológicos, marcadores autoinmunitarios e inmunología. 
La biopsia cutánea presentaba un infiltrado inflamatorio de predominio eosinófilo con tinción negativa para Tzank.

\section{Evolución}

Ante la sospecha de neumonía por varicela en paciente inmunocompetente se inició aciclovir endovenoso, que se suspendió una vez evaluada la negatividad de las muestras microbiológicas. Paralelamente, se inició prednisona a dosis de $1 \mathrm{mg} / \mathrm{kg} /$ día. En las primeras 48-72 horas la paciente empeoró respiratoriamente precisando oxígeno con gafas de alto flujo y monitorización en la unidad de cuidados intensivos. Posteriormente se decidió aumentar la dosis de corticoides hasta $1,5 \mathrm{mg} / \mathrm{kg} /$ día.

Progresivamente presentó mejoría de la función respiratoria y de las lesiones cutáneas, y normalizó el perfil hepático.

Una vez dada de alta, se siguió en consultas con descenso progresivo en la dosis de corticoides hasta su retirada a los seis meses. En análisis consecutivos, se objetivó desaparición de la eosinofilia sin reaparición de los síntomas.

Con la sospecha clínica de síndrome de DRESS se aplicaron las escalas establecidas para su diagnóstico (Japanese group criteria y los criterios de Kardaun et al.) que se muestran en la tabla 2, y, una vez descartadas las posibles causas de eosinofilia con afectación sistémica (infecciosas, neoplásicas y neoplasias hematológicas, reumatológicas, enfermedades pulmonares y por exposición), se diagnosticó de probable síndrome de DRESS en relación a suplementos yodados.

\section{Diagnóstico}

Síndrome de DRESS secundario a un suplemento yodado.

\section{Discusión y conclusiones}

El síndrome de DRESS es una enfermedad compleja cuya patogenia involucra la hipersensibilidad a un fármaco, factores inmunológicos y la reactivación viral, especialmente, del VHS-64 ${ }^{4}$. En numerosos estudios, se ha demostrado la implicación de fármacos como el alopurinol, los anticomiciales (carbamazepina) y algunas sulfonamidas (dapsona). No obstante, solo hay tres casos publicados de la asociación entre yodo y síndrome de DRESS; dos con yodo tópico ${ }^{6,7}$ y otro tras la administración de contraste yodado para realizar un $\mathrm{TC}^{8}$.
Por otro lado, la mortalidad en el síndrome DRESS está relacionada con el grado de afectación sistémica (cardíaca, hepática, renal o pulmonar). La afectación pulmonar es muy poco frecuente, con una prevalencia que oscila entre un 5-33\% $\%^{9,10}$ estando este rango tan amplio relacionado con la baja descripción de la afectación pulmonar y la variabilidad de la misma, que incluye desde clínica inespecífica como disnea limitada, hasta derrame pleural, neumonitis intersticial, nódulos pulmonares o síndrome de distrés respiratorio.

En ocasiones, la afectación pulmonar puede preceder a la afectación cutánea, que es la manifestación más frecuente, generando un error diagnóstico en forma de neumonía, como el caso que nos ocupa ${ }^{10}$. Se desconocen los factores predisponentes para el desarrollo de afectación pulmonar, si bien se ha postulado que la patología pulmonar previa podría ser un desencadenante de la afectación de este órgano en el síndrome de DRESS ${ }^{10}$

Dada la presentación poco frecuente de la afectación pulmonar en el síndrome de DRESS, se debe hacer un diagnóstico diferencial amplio, que incluya causas infecciosas y no infecciosas para llegar al diagnóstico (uno de los criterios de RegiSCAR es haber descartado causas autoinmunes e infecciosas).

En nuestro caso, la ausencia de un fármaco precipitante, y la resolución del cuadro al suspender el suplemento yodado, apoya nuestro diagnóstico. Por otro lado, y teniendo en cuenta los criterios de causalidad de Hill ${ }^{11}$, el caso muestra una fuerte intensidad de relación entre el inicio del suplemento yodado y la reacción sistémica (secuencia temporal favorable, plausibilidad biológica, y especificidad de asociación, ya que no se ha podido imputar a otro fármaco), si bien no se ha podido demostrar una evidencia experimental sometiendo a la paciente de nuevo al suplemento por la gravedad del cuadro.

En resumen, ante un paciente con afectación sistémica e hipereosinofilia se deben descartar las principales causas de esta con estudios microbiológicos, inmunológicos, anatomopatológicos y con pruebas de imagen. Además, se debe indagar en el inicio de un nuevo fármaco, o en el cambio de algún tratamiento, sin olvidar los productos de herboristería o los suplementos.

Ante la sospecha de síndrome de DRESS, son útiles los criterios diagnósticos, la suspensión inmediata del fármaco en cuestión, así como el inicio de corticoterapia a altas dosis.

\begin{tabular}{|c|c|c|}
\hline Manifestación clínica/laboratorio & Puntuación & Paciente \\
\hline Fiebre $>38,5^{\circ} \mathrm{C}$ & 0 & sí \\
\hline Erupción cutánea aguda & 1 & sí \\
\hline Biopsia cutánea sugestiva de DRESS & 0 & No aplica \\
\hline Sospecha de reacción secundaria a fármacos & 1 & Sí \\
\hline Eosinofilia $>700 \mathrm{~mm} 3$ o > 10\% & 2 & sí \\
\hline Linfocitos atípicos & 0 & NO \\
\hline Adenopatías $\geq$ de 2 lugares & 1 & sí \\
\hline Afectación de al menos un órgano interno & 1 & Sí \\
\hline Resolución del exantema en 15 días & 1 & Sí \\
\hline Descartadas otras causas* & 1 & sí \\
\hline Puntuación total & 8 & 8 \\
\hline
\end{tabular}

Tabla 2. Índice diagnóstico del síndrome de DRESS. Registro Europeo de las Reacciones Adversas Cutáneas Graves (RegiSCAR). http://www.regiscar.org/esp/ Project.html.

Puntuación final < 2: excluye; puntuación final 2-3: caso posible; puntuación final 4-5: caso probable; y puntuación final > 5: caso definitivo. 


\section{Bibliografía}

1. Ocampo-Garza J, Ocampo-Garza SS, Martínez-Villarreal JD, Barbosa-Moreno LE, Guerrero-González GA, Ocampo-Candiani J. Reacción por drogas con eosinofilia y síntomas sistémicos (síndrome de DRESS): Estudio retrospectivo de nueve casos. Rev Med Chil. 2015; 143(5): 577-83. doi: 10.4067/S003498872015000500004.

2. Lee HY. Drug reaction with eosinophilia and systemic symptoms (DRESS). In: UpToDate, Mockenhaupt M, (Ed). Corona R, (Ed). UpToDate, Waltham, MA 2020. Disponible en: http://www.uptodate.com

3. Kardaun SH, Sekula P, Valeyrie-Allanore L, Liss Y, Chu CY, Creamer D, et al. Drug reaction with eosinophilia and systemic symptoms (DRESS): an original multisystem adverse drug reaction. Results from the prospective RegiSCAR study. Br J Dermatol 2013; 169: 1071-80. doi: 10.1111/bjd.12501.

4. Cho YT, Yang CW, Chu CY. Drug Reaction with Eosinophilia and Systemic Symptoms (DRESS): An interplay among drugs, viruses, and immune system. Int J Mol Sci. 2017; 18(6): 1243. doi: 10.3390/ijms18061243.

5. Kohn V, Carrizo D, Arato G, Arroyo F. Síndrome de DRESS en una paciente con fibrosis quística: reporte de un caso pediátrico. Arch Argent Pediatr 2021;119(3): e234-e238. doi: 10.5546/aap.2021.e234.
6. Sterling JB, Heymann WR. Potassium iodide in dermatology: a 19th century drug for the 21st century-uses, pharmacology, adverse effects, and contraindications. J Am Acad Dermatol. 2000; 43(4): 691-7. doi: 10.1067/ mjd.2000.107247.

7. Sowa J, Tsuruta D, Nakanishi T, Kobayashi H, Ishii M. Generalized dermatitis with eosinophilia resulting from allergic contact dermatitis due to povidone iodine. Contact Dermatitis. 2006; 54(3): 174-6. doi: 10.1111/j.01051873.2005.0739g.x.

8. Macías EM, Muñoz-Bellido FJ, Velasco A, Moreno E, Dávila I. DRESS syndrome involving 2 unrelated substances: imipenem and iodinated contrast media. J Investig Allergol Clin Immunol. 2013;23(1):56-7.

9. Cacoub P, Musette P, Descamps V, Meyer O, Speirs C, Finzi L, et al. The DRESS syndrome: a literature review. Am J Med 2011; 124(7): 588-97. doi: 10.1016/j. amjmed.2011.01.017.

10. Taweesedt PT, Nordstrom CW, Stoeckel J, Dumic I. Pulmonary Manifestations of Drug Reaction with Eosinophilia and Systemic Symptoms (DRESS) Syndrome: A Systematic Review. Biomed Res Int. 2019 Sep 24; 2019: 7863815. doi: 10.1155/2019/7863815.

11. Hill AB. The environment and disease: association or causation? Proc R Soc Med. 1965; 58(5): 295-300. 